\title{
Serious Adverse Events and the Modafinil Augmentation Study
}

\author{
To the Editor:
}

March 2, 2006

I have many questions regarding the completed suicide and the case of leukopenia/neutropenia in the February 2006 article by Thase and colleagues, "Modafinil Augmentation of SSRI Therapy in Patients with Major Depressive Disorder and Excessive Sleepiness and Fatigue: A 12-Week Open-Label, Extension Study."

Can we get more details on these two serious adverse events?

Did either or both of these patients receive placebo before getting modafinil?

How far into the study did the events occur?

What drugs and dosages were they taking at the time?

Why did the authors conclude the suicide and the leukopenia/neutropenia were unrelated to the drug trial?

In my experience, a completed suicide and a case of leukopenia/neutropenia among 250 patients over an 8-week drug trial seems unusual. Since I supplement with modafinil, I find the partial report unsettling. I think in some fashion the article should be amended with this information.

Regards,

Jerald Block, MD

Portland, OR

\section{REFERENCE}

1. Thase ME, Fava M, DeBattista C, Arora S, Hughes RJ. Modafinil augmentation of SSRI therapy in patients with major depressive disorder and excessive sleepiness and fatigue: a 12-week, open-label, extension study. CNS Spectr. 2006;11(2):93-102.

Dr. Block is clinical teaching faculty at Oregon Health \& Science University and in private practice in Portland, Oregon.

Disclosure: Dr. Block does not have an affiliation with or financial interest in any organization that might pose a conflict of interest.
The Authors respond:

April 5, 2006

We appreciate the opportunity to respond to Dr. Block's request for more information on our report, "Modafinil Augmentation of SSRI Therapy in Patients with Major Depressive Disorder and Excessive Sleepiness and Fatigue: A 12-Week Open-Label, Extension Study." This report was the extension study to an 8-week double-blind study in which patients taking SSRIs who had incompletely responded to therapy were randomly assigned to modafinil or matching placebo. ${ }^{1}$ It is important to understand that all of the participants in this 12-week extension study had received at least 16 weeks of selective serotonin reuptake inhibitor therapy (with or without active modafinil for 8 weeks during the double-blind phase) prior to beginning open-label modafinil therapy.

We agree that these two serious adverse events are rare in clinical studies of patients with major depressive disorder (MDD) and, thus, warrant a closer look. The patient who experienced leukopenia/neutropenia was a 37-year-old male with MDD (since 1991) who was receiving sertraline $150 \mathrm{mg} /$ day. The patient, who had a history of lower back pain and substance abuse, received placebo during the 8-week double-blind phase. At baseline of the double-blind phase, his white blood cell (WBC) count and absolute neutrophil count (ANC) were low (WBC: $3.7 \times$ $10^{9} / \mathrm{L}$, normal range $=3.8-10.8 \times 10^{9} / \mathrm{L}$; ANC: $1.7 \times$ $10^{9} / \mathrm{L}$, normal range $=1.8-8.0 \times 10^{9} / \mathrm{L}$ ). He was a responder to placebo therapy and his 17-item Hamilton Rating Scale for Depression (HAM-D ${ }_{17}$ ) score decreased from 14 to 3 . The patient's WBC count after 8 weeks of placebo was again low $\left(2.9 \times 10^{9} / \mathrm{L}\right)$, as was his ANC $\left(1.4 \times 10^{9} / \mathrm{L}\right)$.

During the open-label period, while the patient continued taking sertraline, modafinil was initiated at $100 \mathrm{mg} / \mathrm{day}$ for 3 days and then continued at an average dose of $200 \mathrm{mg} / \mathrm{day}$. On days 33 and 42, the patient's WBC counts were clinically significantly low $\left(2.1 \times 10^{9} / \mathrm{L}\right.$ on both days) and his ANCs were clinically significantly 
abnormal $\left(0.7 \times 10^{9} / \mathrm{L}\right.$ on both). Therefore, he was withdrawn from study therapy on day 42 (last dose of modafinil was day 41) and the blind (which masked assignment in the double-blind phase) was broken. Because the pattern of low WBCs and ANCs had been present at baseline and appeared to worsen during treatment with placebo and sertraline during the double-blind phase, the investigator rated these events as unlikely to be related to modafinil. After withdrawal from the study, this patient was lost to follow-up. No further information about his outcome is available.

The patient who committed suicide was a 40year-old white man with a history of MDD (since 1997) who was receiving sertraline $100 \mathrm{mg} / \mathrm{day}$ and bupropion $300 \mathrm{mg} /$ day. The patient had a history of migraine, sinus draining, inguinal hernia repair, herniated disk, ganglion cyst, carpal tunnel syndrome, bone spur, and sensitivity to penicillin and sulfa drugs. He received modafinil $200 \mathrm{mg} /$ day in the double-blind phase. The patient was a responder during the double-blind study; his HAM-D 17 total score decreased from 15 to 5 .

In the open-label phase, the patient received an initial dose of modafinil $100 \mathrm{mg} / \mathrm{day}$ for 3 days before titration to $200 \mathrm{mg} /$ day. The patient also took paracetamol $250 \mathrm{mg} /$ day for headaches and the common cold, for which he also took Alka Seltzer. The patient had also received lidocaine (local anesthesia for surgery for carpal tunnel syndrome/bone spur removal). At visit 1 of the open-label period (day 25 of the open-label period), his condition remained improved (in relation to before starting double-blind therapy). However, he did report experiencing a relationship problem that was causing an increase in depressive symptoms, according to the investigator's reporting form. The patient did not express any suicidal ideation to the investigator, and the HAM-D 17 and Montgomery-Åsberg Depression Rating Scale items for suicidal ideation were 0 , as they had been throughout the course of the study. Three days later, on day 28 of the open-label phase (day 87 since starting modafinil therapy), the patient committed suicide (by cutting his wrists and neck with a razor blade). The last day of dosing was reported as day 84 . The investigator determined that the suicide was not attributable to treatment with modafinil because of the patient's overall response to treatment and because of the temporal relationship between the reported relationship problems and the suicide.
In this study, as with any clinical study, it is the treating psychiatrist, not the authors of the manuscript, who assesses the relationship of all adverse events to study drug. In reviewing the history associated with these two serious adverse events, the investigators determined that the events were not related to the study drugs and we, the authors, saw no reason to disagree with their assessment.

Nevertheless, the occurrence of relatively infrequent serious adverse events needs to be monitored carefully to ensure that a novel therapy is not associated with some relatively rare pharmacologic or behavioral toxicity. To this end, it is important to note that the safety of modafinil has been evaluated in $>3,500$ patients in clinical studies, of whom $>2,000$ were patients with excessive sleepiness associated with a disorder of sleep and wakefulness. In these studies, modafinil was not found to have a clinically significant effect on WBC count or, for that matter, on any hematologic variable. With respect to behavioral toxicity, there were no reports of suicide, suicide attempts, or suicidal ideation in randomized, double-blind clinical studies of modafinil for the treatment of excessive sleepiness associated with narcolepsy, obstructive sleep apnea/hypopnea syndrome, or shift-work sleep disorder. There are postmarketing reports of suicide, suicide attempts, and suicidal ideation in patients who were treated with modafinil. However, the number of such reports does not suggest a pattern and, in such cases, determination of causality is difficult due to the number of confounding factors that can contribute to these events.

With respect to the broader issue of suicide in patients receiving antidepressants, we agree that this is an important public health matter, and the literature offers varied findings on risk of suicide or suicidal ideation with antidepressant therapy. ${ }^{2-4}$ The Food and Drug Administration is working with manufacturers of commonly prescribed antidepressants to increase awareness of this issue among clinicians and to evaluate whether such agents are associated with an increased risk. ${ }^{5}$ The agency advises clinicians to monitor adult patients being treated with antidepressant medications closely for worsening of depression and increased suicidal thinking or behavior, particularly early in treatment or when the dose is either increased or decreased. It is recommended that any patient with worsening of symptoms or an increase in suicidal thinking or behavior be evaluated by a healthcare professional. Monitoring is also recommended when patients with MDD are taken off medication. 
Further information from the FDA on this topic is anticipated. As is evident, unfortunately, in the case of the patient who completed suicide, even close monitoring and an apparent response to treatment were not sufficient to negate his risk.

\author{
Sincerely, \\ Michael E. Thase, MD \\ Pittsburgh, PA \\ Maurizio Fava, MD \\ Boston, MA \\ Charles DeBattista, MD \\ Stanford, CA \\ Sanjay Arora, PhD \\ Frazer, PA, and \\ Rod J. Hughes, PhD' \\ Frazer, PA
}

\section{REFERENCES}

1. Fava $M$, Thase ME, DeBattista C. A multicenter, placebo-controlled study of modafinil augmentation in partial responders to selective serotonin reuptake inhibitors with persistent fatigue and sleepiness. J Clin Psychiatry. 2005;66:85-93

2. Khan A, Khan S, Kolts $R$, Brown WA. Suicide rates in clinical trials of SSRIs, other antidepressants, and płacebo: Analysis of FDA reports. Am J Psychiatry. 2003;160:790-792.

3. Ferguson $D$, Doucette $S$, Glass $K C$, et al. Association between suicide attempts and selective serotonin reuptake inhibitors: systematic review of randomized controlled trials. BMJ. 2005;330:396-402.

4. Gunnell D, Saperia J, Ashby D. Selective serotonin reuptake inhibitors (SSRIs) and suicide in adults: meta-analysis of drug company data from placebo-controlled, randomised controlled trials submitted to the MHRA's safety review. BMJ. 2005;330:385.

5. FDA Public Health Advisory. Suicidality in adults being treated with antidepressant medications. Available at: http://www.fda.gov/cder/drug/advisory/SSRl200507.htm. June 30, 2005. Accessed March 17, 2006.
Dr. Thase is chief of the Division of Adult Academic Psychiatry and director of the Mood Disorders Trealment and Research Program at Western Psychiatric Institute and Clinic at the University of Pittsburgh Medical Center in Pennsylvania. Dr. Fava is director of the Depression Clinical and Research Program at Massachusetts General Hospital in Boston. Dr. DeBattista is director of the Depression Research Clinic at Stanford University in California. Dr. Arora is a director in the Biostatistics Department at Cephalon, Inc., in Frazer, Pennsylvania. Dr. Hughes is vice president of the Scientific Communications Department at Cephalon, Inc., in Frazer.

Disclosure: Dr. Thase has been a consultant for AstraZeneca, BristolMyers Squibb, Cephaion, Cyberonics, Eli Lilly, Forest, GlaxoSmithKline, Janssen, Novartis, Organon, Pfizer, Sepracor, Shire US, and Wyeth; and he is on the speaker's bureau of AstraZeneca, Bristol-Myers Squibb, Cyberonics, Eli Lilly, GlaxoSmithKline, Sanofi Aventis, and Wyeth. Dr. Fava has been a consultant to Cephalon; has received research support from Abbott, Lichtwer, and Lorex; has receivedhonoraria from Bayer, Biovail, BrainCells, Compellis, Cypress, FabreKramer, Grunenthal, Janssen, MedAvante, Sepracor, and Somerset; and has received research support/honoraria from Aspect Medical Systems, AstraZeneca, Bristol-Myers Squibb, Cephalon, Eli Lilly, Forest, GlaxoSmithkline, Johnson \& Johnson, Novartis, Organon, Pharmavite, Pfizer, Roche, Sanofi/Synthelabo, Solvay, and Wyeth. Dr. DeBattista has been a consultant for Cephalon; has received grant/research support from Cephalon, Corcept, Eli Lilly, GlaxoSmithKline, and Wyeth; and is on the speaker's bureau of Cephalon, Corcept, Cyberonics, Eli Lilly, GlaxoSmithKline, and Pfizer. Drs. Arora and Hughes do not have any affiliation or financial interested in any organization that might pose a conflict of interest.

Please send letters to the editor to: CNS Spectrums, c/o Jack M. Gorman, MD, 333 Hudson St., 7th Floor, New York, NY 10013; E-mail: jrr@mblcommunications.com.

\title{
CME1 Now Available Online at www.mblcommunications.com
}

\section{ROUNDTABLE MONOGRAPH SUPPLEMENT}

\author{
Focusing on issues impacting practice and patient care
}

\section{Incorporating Pharmacogenetics Into Clinical Practice: Reality of a New Tool in Psychiatry}

\author{
Moderator: \\ David Mrazek, MD \\ Faculty: \\ Jordan W. Smoller, MD, ScD, \\ and Jose de Leon, MD
}

Or to order a published supplement, please E-mail jrr@mblcommunications.com

Supported through an unrestricted educational grant from Roche Molecular Systems 
FIRST

IN A NOVEL

CLASS OF

SLEEP AGENTS

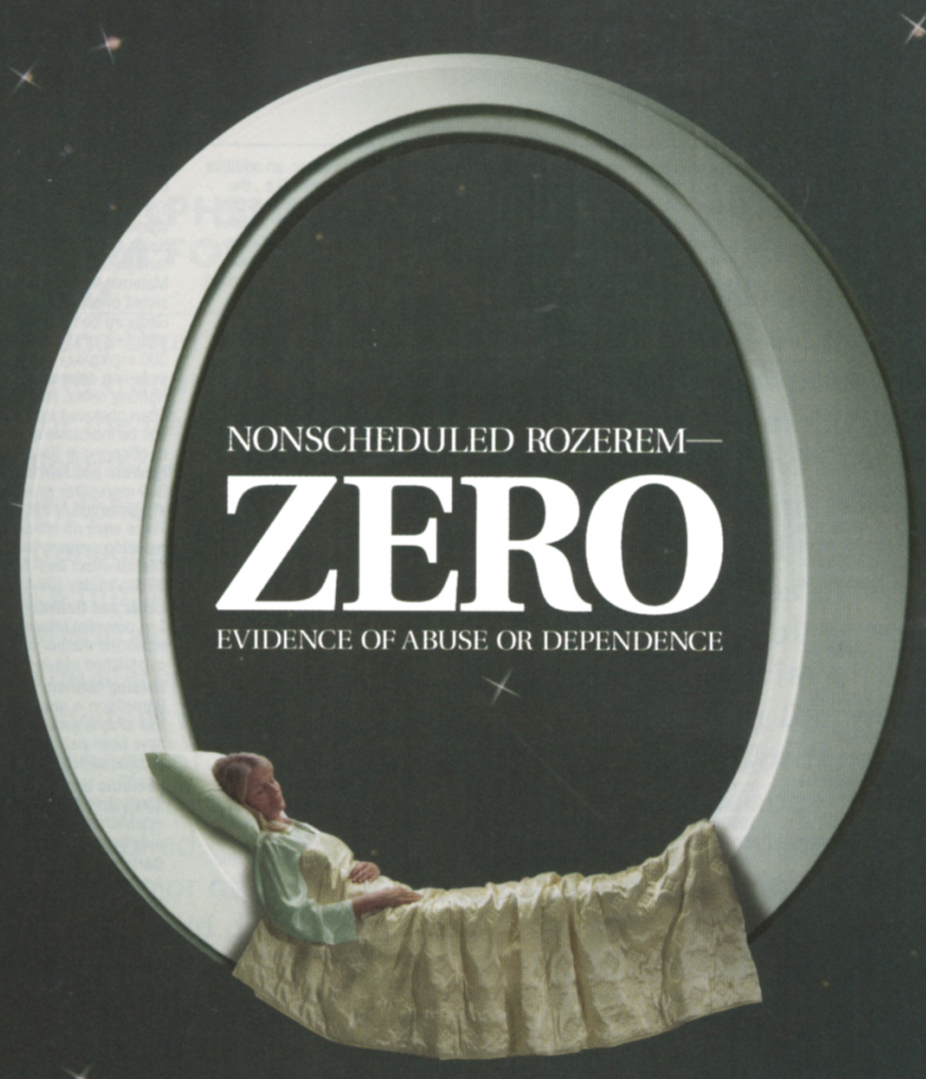

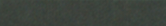

\section{Clinical studies show no evidence of potential abuse, ${ }^{*}$ dependence, or withdrawal}

- First and only-nonscheduled prescription ${ }^{+}$ insomnia medication...not a controlled substance and approved for long-term use'

- First and only - prescription insomnia medication that targets the normal sleep-wake cycle'

- First and only - prescription insomnia medication with no evidence of abuse potential in clinical studies

- First and only - prescription insomnia 'medication that does not act by CNS depression'

- Promote sleep with Rozerem - patients who took Rozerem fell asleep faster than those who took placebo

\section{Please visit www.rozerem.com}

*A randomized, single-center, double-blind, dose run-up study $(\mathrm{N}=6)$ and a single-center, randomized, double-blind, placebo-controlled crossover study $(\mathrm{N}=14)$ specifically assessed the abuse liability of Rozerem in patients with a history of substance abuse.
Rozerem is indicated for the treatment of insomnia characterized by difficulty with sleep onset. Rozerem can be prescribed for long-term use. Rozerem should not be used in patients with hypersensitivity to any components of the formulation, severe hepatic impairment, or in combination with fluvoxamine. Failure of insomnia to remit after a reasonable period of time should be medically evaluated, as this may be the result of an unrecognized underlying medical disorder. Hypnotics should be administered with caution to patients exhibiting signs and symptoms of depression. Rozerem has not been studied in patients with severe sleep apnea, severe COPD, or in children or adolescents. The effects in these populations are unknown. Exercise caution if consuming alcohol in combination with Rozerem. Rozerem has been associated with decreased testosterone levels and increased prolactin levels. Health professionals should be mindful of any unexplained symptóms possibly associated with such changes in these hormone levels. Rozerem should not be taken with or immediately after a high-fat meal. Rozerem should be taken within 30 minutes before going to bed and activities confined to preparing for bed. The most common adverse events seen with Rozerem that had at least a $2 \%$ incidence difference from placebo were somnolence, dizziness, and fatigue.

Please see adjacent Brief Summary of Prescribing Information.

\section{ORozerem.}




\section{Brief Summary of Prescribing Information
$05-1114$ \\ ROZEREMTM}

INDICATIONS AND USAGE

NOICATEONS AND USAGE ROZEREM is indicated for
culty with sleep onset.

CONTRAINOICATIOHS

作

WARNINGS

Since sleep disturbances may be the presenting manifestation of a physical and/or psychiatric disorder, symptormatic treatment of insomnia should be
initiated only atter a careful evaluation of the patient. The tail ure of insomnia to remit after a reasonable period of treatment may indicate the presence of a primary psychiatric and/or medical illness that should be evaluated.

Worsening of insomnia, or the emergence of new cognitive or behavioral physical disorder and requires further evaluation of the patient. As with other hypnotics, exacerbation of insomnia and emergence of cognitive and behav-
ioral abnormalities were seen with ROZEREM during the clinical develooment ioral abno
program.

ROZEREM should not be used by patients with severe hepatic impairment. ROZEREM should not be used in combination with fluvoxamine (see PRECAUTIONS: Drug Interactions

A variety of cognitive and behavior changes have been reported to occur in association with the use of hypnotics. In primarily depressed patients, worsening of depression, including suiciol

Patients should avoid engaging in hazardous activities that require concentration (such as operating a motor vehicle or heavy machinery) after taking

After taking ROZEREM, patients should confine their activities to those necessary to prepare for bed.

PAECAUTIONS

ROZEREM has not been studied in subjects with severe sleep apnea or severe COPD and is not recommended for use in those populations. Patients should be advised to exercise caution if they consume alcohol in combination with ROZEREM.

\section{Use in Adoloscents and Children}

ROZLR A has been associated with an effect on reproductive hormones in adults, e.g. decreased testosterone levels and increased prolactin levels. It is
not known what effect chronic or even chronic intermittent use of ROZEREM may have on the reproductive axis in developing humans (see Pediatric Use) Intormation for Patients

Patients should be advised to take ROZEREM within $\mathbf{3 0}$ minutes prior to going to bed and should confine their activities to those necessary to prepare

Patients should be advised to avoid engaging in hazardous activities (such as operating a motor vehicle or heavy machinery) after taking ROZEREM. Patients should be advised that the
immediately after a high fat meal.

Patients should be advised to consult their health care provider if they experience worsening of insomnia or any new behavioral signs or symptoms of

Patients should consult their health care provider if they experience one of the following: cessation of menșes or gaiactorrhea in females, decreased ibido, or problems with fertilly.

Laboratory Tests

No standard monitoring is required.

For patients presenting with unexplained amenorrhea, galactorrhea, decreased
libido, or problems with fertility assessment of prolactin levels and testos-

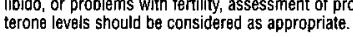

Drug Interactions

ROZEREM has a highly variable inter-subject pharmacokinetic profile (approximately $100 \%$ coefficient of variation in $C_{\max }$ and AUC). As noted above, CYP1A2 is the major isozyme involved in the metabolism of
ROZEREM; the CYP2C subtamily and CYP3A4 isozymes are also involved to a minor degres.

Effects of Other Drugs on ROZEREM Metabolism

Fiuvoxamine (strong CYP1A2 inhibitor): When fluvoxamine $100 \mathrm{mg}$ twice daily was administered for 3 days prior to single-dose co-administration
ROZEREM $16 \mathrm{mg}$ and fluvoxamine, the $A U \mathrm{C}_{0-\text {-m }}$ for ramelteon increased ROZEREM $16 \mathrm{mg}$ and fluvoxamine, the AUC $\mathrm{C}_{\text {-inn }}$ for ramelteon increased
approximately 190 -1old, and the $\mathrm{C}_{\text {max }}$ increased approximately 70 -1old, compared to ROZEREM administered alone. ROZEREM should not be used in combination with fluvoxamine (See WARNINGS). Other less potent CYP1A2 inhibitors have not been adequately studied. ROZEREM should be
administered with caution to patients taking less strong CYP1A2 inhibitors. Ritampin (strong CYP enzyme inducer): Administration of rifampin $600 \mathrm{mg}$ once daily for 11 days resulted in a mean decrease of approximately $80 \%$ $(40 \%$ to $90 \%$ ) in total exposure to ramelteon and metabolite $\mathrm{M}-\mathrm{H}$, (both
$A \cup \mathrm{C}_{0 . \text {-int }}$ and $\mathrm{C}_{\text {max }}$ ) after a single $32 \mathrm{mg}$ dose of ROZEREM. Efficacy may be $A U C_{0.1 n f}$ and $C_{\text {max }}$ after a single $32 \mathrm{mg}$ dose of ROZEREM. Efficacy may be
reduced when ROZEREM is used in combination with strong CYP enzyme inducers such as rifampin.

Ketoconazole (strong CYP3A4 inhibitor): The AUC $\mathrm{C}_{\text {-inn }}$ and $\mathrm{C}_{\max }$ of ramelteon increased by approximately $84 \%$ and $36 \%$, respectively, when a single $16 \mathrm{mg}$ $200 \mathrm{mg}$ twice daily administration, compared to administration of ROZEREM alone. Similar increases were seen in M-II pharmacokinetic variables.
ROZEREM should be administered with caution in subjects taking strong CYP3A4 inhibitors such as ketoconazole.

Fluconazole (strong CYP2C9 inhibitor): The total and peak systemic exposure
(AUC $C_{0.10}$ and $C_{\max }$ ) of ramelteon after a single $16 \mathrm{mg}$ dose of ROZEREM was increased by approximately $150 \%$ when administered with fluconazole. Similar increases were also seen in M-11 exposure. ROZEREM should be
administered with caution in subjects taking strong CYP2C9 inhibitors such

Interaction studies of concomitant administration of ROZEREM with fluoxetine (CYP2D6 inhibitor), omeprazole (CYP1A2 inducer/CYP2C19 inhibitor), did not produce clinically meaningtul changes in either peak or total expo-

Ettects of AOZEREM on Metabolism of Other Drugs

Concomitant administration of ROZEREM with omeprazole (CYP2C19 substrate), dextromethorphan (CYP2D6 substrate), midazolam (CYP3A4 substrate), theophylline (CYP1A2 substrate), digoxin (p-glycoprotein sub-

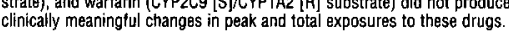

Etfect of Alcohol on Rozerem

Accohol: With single-dose, daytime co-administration of ROZEREM $32 \mathrm{mg}$,
and alcohol $(0.6 \mathrm{~g} / \mathrm{kg}$ ), there were no clinically meaning ful or statistically sion Q2006 Takeda Pharmaceuticals North America, Inc. nificant effects on peak or total exposure to ROZEREM. However, an additive effect was seen on some measures of psychomotor performance (i.e., the Digit Symbol Substitution Test, the Psychomotor Vigilance Task Test, and a effect was seen on the Delayed Word Recognition Test. Because alcohol by itself impairs pertormance and the intended effect of $R O Z F R E M$ is to promote sleep, patients should be cautioned not to consume alcohoi when using Drugh Laboratory Test Interactions

tests in addition known to interfere with commonly used clinical laboratory vitro data indicate that ramelteon does not cause falsepositive results for benzodiazepines, opiates, barbiturates, cocaine, cannabnoids, or am
in vitro.

Carcinogenesis, Mutagenesis, and Impaimment of Fertility

In a two-year carcinogenicity study, $86 \mathrm{CCF}_{1}$ mice were administered ramelteo at doses of $0,30,100,300$, or $1000 \mathrm{mg} / \mathrm{kg} /$ day by oral gavage. Male mice exhibited a dose-related increase in the incidence of hepatic tumors at dose
levels $\geq 100 \mathrm{mg} / \mathrm{kg} / \mathrm{day}$ including hepatic adenoma, hepatic carcinoma, and hepatoblastoma. Female mice developed a dose-related increase in the
dence of hepatic adenomas at dose levels $>300 \mathrm{mg} / \mathrm{kg} / \mathrm{day}$ and hepatic carcinoma at the $1000 \mathrm{mg} / \mathrm{kg} / \mathrm{day}$ dose level. The no-effect level for hepatic carcinoma at the
tumors in male mice was $30 \mathrm{mg} / \mathrm{kg} / \mathrm{day}$ (103-times and 3 -times the therapeu-
tic exposure to rameiteon and the active metabolite $M-11$, respectively, at the meximum recommended human dose [MRHD] based on an area-under-the-
curve [AUC] comparison). The no-effect level for hepatic tumors in female
mice was $100 \mathrm{mg} / \mathrm{kg} /$ day $(827$-times and 12-times the therapeutic exposure mice was $100 \mathrm{mg} / \mathrm{kg} / \mathrm{day}$ ( 827 -times and 12 -times the therapeutic

In a two-year carcinogenicity study conducted in the Sprague-Dawley rat 250 or $1000 \mathrm{mg} / \mathrm{kg} / \mathrm{day}$ by oral gavage. Male rats exhibited a dose-related increase in the incidence of hepatic adenoma and benign Leydig cell tumor of the testis at dose levels $\geq 250 \mathrm{mg} / \mathrm{kg} /$ day and hepatic carcinoma at the $1000 \mathrm{mg} / \mathrm{kg} /$ day dose level. Female rats exhibited a dose-related increase in the incidence of hepatic adenoma at dose level $\mathrm{s} \geq 60 \mathrm{mg} / \mathrm{kg} / \mathrm{day}$ and hepatic carcinoma at the $1000 \mathrm{mg} / \mathrm{kg} / \mathrm{day}$ dose level. The no-effect level for heparc
tumors and benign Leydig cell tumors in male rats was $60 \mathrm{mg} / \mathrm{kg} / \mathrm{day}$ tumors and benign Leydig cell tumors in male rats was $60 \mathrm{mg} / \mathrm{kg} / \mathrm{day}$
$(1,429$-times and 12 -times the therapeutic exposure to ramelteon and $\mathrm{M}$ (1,429-times and 12-times the therapeutic exposure to ramelteon and $M$ -
respectively, at the MRHD based on ALC). The no-effect level for hepatic tumors in female rats was $15 \mathrm{mg} / \mathrm{kg} / \mathrm{day}$ ( 472 -times and 16-times the therapeutic exposa
based on AUC)

The development of hepatic tumors in rodents following chronic treatment with non-genotoxic compounds may be secondary to microsomal enzym with non-genotoxic compounds may be secondary to microsomal enzyme humans. Leydig cell tumor development following treatment with nongenotoxic compounds in rodents has been linked to reductions in circulating testosterone levels with compensatory increases in luteinizing hormone
release, which is a known proliferative stimulus to Leydig cells in the rat release, which is a known proliferative stimulus to Leydig cells in the
testis. Rat Leydig cells are more sensitive to the stimulatory effects of testis. Rat Leydig cells are more sensitive to the stimulatory effects of
luteinizing hormone than human Leydig cells. In mechanisfic studies conducted in the rat, datly ramelteon administrot for 4 weeks was associated with a reduction in plasma testosterone levels. In the same study, luteinizing hormone levels were elevated over a 24 ho
period after the last ramelteon treatment; however, the durability of this luteinizing hormone finding and its support for the proposed mechanist explanation was not clearly established.

Although the rodent tumors observed following ramelteon treatment occurred at plasma levels of ramelteon and M-II in excess of mean clinical plasma concentrations at the MRHD, the relevance of both rodent
benign rat Leydig cell tumors to humans is not known.

Mutagenesis

Ramelteon was not genotoxic in the following: in vitro bacterial reverse mutotion (Ames) assay; in vitro mammalian cell gene mutation assay using the

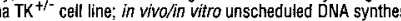
assay in rat hepatocytes; and in in vivo micronucleus assays conducted in mouse and rat. Ramelteon was positive in the chromosomal aberration as
in Chinese hamster lung cells in the presence of 59 metabolic activation. Separate studies indicated that the concentration of the M-II metabolite formed by the rat liver $S 9$ fraction used in the in vitro genetic toxicology studies described above, exceeded the concentration of ramelteon; therefor the geno
studies.

impairment of Fertility

Ramelteon was administered to male and female Sprague-Dawley rats in an initial tertility and early embryonic development study at dose levels of observed with a ramelteon dose up to $600 \mathrm{mg} / \mathrm{kg}$ /day (786-times higher than the MRHD on a $\mathrm{mg} / \mathrm{m}^{2}$ basis). Irregular estrus cycles, reduction in the number of implants, and reduction in the number of live embryos were noted with dosing femaies at $\geq 60 \mathrm{mg} / \mathrm{kg} /$ day $(79$-times higher than the MRHD on a $\mathrm{mg} / \mathrm{m}^{2}$ basis). A reduction in the number of corpora lutea occurred at the $600 \mathrm{mg} / \mathrm{kg} / \mathrm{day}$ dose level. Administration of ramelteon up to $600 \mathrm{mg} / \mathrm{kg} / \mathrm{day}$
to male rats for 7 weeks had no effect on sperm quality and when the treated to male rats for 7 weeks had no effect on sperm quality and when the treat
male rats were mated with untreated female rats there was no effect on implants or embryos. In a repeat of this study using oral administration of implants or embryos. In a repeat of this study using oral administration of
ramelteon at 20,60 or $200 \mathrm{mg} / \mathrm{kg} / \mathrm{day}$ for the same study duration, females demonstrated irregular estrus cycles with doses $\geq 60 \mathrm{mg} / \mathrm{kg} / \mathrm{day}$, but no effects were seen on implantation or embryo viability. The no-effect dose for

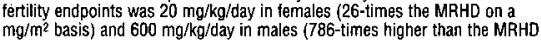
on a $\mathrm{mg} / \mathrm{m}^{2}$ basis) when considering all studies.

Pregnancy: Pregnancy Category c

Ramelteon has been shown to be a developmental teratogen in the rat whe given in doses 197 times higher than the maximum recommended human
dose [MRHO] on a $\mathrm{mg} / \mathrm{m}^{2}$ basis. There are no adequate and well-controlled studies in pregnant women. Ramelteon should be used during pregnancy only if the potential benefit justifies the potential risk to the fetus.

The effects of ramelteon on embryo-fetal development were assessed in both the rat and rabbit. Pregnant rats were administered ramelteon by oral gavage at doses of $0,10,40,150$, or $600 \mathrm{mg} / \mathrm{kg} /$ day during gestation days $6-17$, toxicity and fetal teratogenicity was observed at doses greater than or equa to $150 \mathrm{mg} / \mathrm{kg} /$ day. Maternal toxicity was chlefly characterized by decreased body weight and, at $600 \mathrm{mg} / \mathrm{kg} / \mathrm{day}$, ataxia and decreased spontaneous mo ment. At maternally toxic doses $(150 \mathrm{mg} / \mathrm{kg} /$ day or greater), the fetuses demonstrated visceral malformations consisting of diaphragmatic hernia and $600 \mathrm{mg} / \mathrm{kg} / \mathrm{day}$, reductions in fetal body weights and malformations including cysts on the external genitalia were additionally observed. The no-effect level for teratogenicity in this study was $40 \mathrm{mg} / \mathrm{kg} / \mathrm{day}(1,892$-times and 45 -times higher than the therapeutic exposure to ramelteon and the active metabol
$M-11$, respectively, at the MRHD based on an area-under-the-curve [AUC] M-ll, respectively, at the MRHD based on an area-under-the-curve [AUC]
comparison). Pregnant rabbits were administered ramelteon by oral gavag at doses of $0,12,60$, or $300 \mathrm{mg} / \mathrm{kg} / \mathrm{day}$ during gestation days $6-18$, which is the period of organogenesis in this species. Although maternal toxicity was apparent with a ramelteon dose of $300 \mathrm{mg} / \mathrm{kg} / \mathrm{day}$, no evidence of fetal effects
or teratogenicity was associated with any dose level. The no-effect level for or teratogenicity was associated with any dose level. The no-effect level 1 er
teratogenicity was, therefore, $300 \mathrm{mg} / \mathrm{kg} / \mathrm{day}$ (11,862-times and 99 -times s502-0171-1 higher than the therapeutic
the MRHD based on AUC)

The effects of ramelteon on pre- and post-natal development in the rat were studied by administration of ramelteon to the pregnant rat by oral gavage at doses of $0,30,100$, or $300 \mathrm{mg} / \mathrm{kg} / \mathrm{day}$ from day 6 of gestation through parMaternal toxicity was noted at doses of $100 \mathrm{mg} / \mathrm{kg} / \mathrm{day}$ or greater and consisted of reduced body weight gain and increased adrenal gland weight. Reduced body weight during the post-weaning period was also noticed in offspring of the groups given $100 \mathrm{mg} / \mathrm{kg} /$ day and higher. Ottspring in the
$300 \mathrm{mg} / \mathrm{kg} / \mathrm{day}$ group demonstrated physical and developmental delays including delayed eruption of the lower incisors, a delayed acquisition of the righting reflex, and an alteration of emotional response. These delays are still be indicative of developmental delay. An apparent decrease in the viability of offspring in the $300 \mathrm{mg} / \mathrm{kg} / \mathrm{day}$ group was likely due to altered maternal behavior and function observed at this dose level. Offspring of the
$300 \mathrm{~m} / \mathrm{kg} / \mathrm{day}$ group also showed evidence of diaphrapmatic hernia, a find ing observed in the embryo-fetal development study previously described resulting progeny were not different from those of venicie-treated offspring The no-effect level for pre-and postnatal development in this study was
$30 \mathrm{mg} / \mathrm{kg} / \mathrm{day}$ ( 39 -times higher than the MRHD on a $\mathrm{mg} / \mathrm{m}^{2}$ basis).

The potential effects of ROZEREM on the duration of labor and/or delivery, fo either the mother or the fetus, have not been studied. ROZEREM has no Nursing Mothers

Ramelteon is secreted into the milk of lactating rats. It is not known whether this drug is excreted in human milk. No clinical studies in nursing mothers
have been performed. The use of ROZEREM in nursing mothers is not have been perite
recommended.

Pediatric use

Safety and effectiveness of ROZEREM in pediatric patients have not been established. Further study is needed prior to determining that this product may be used safely in pre-pubescent and pubescent patients.

A total of 654 subjects in double-blind, placebo-controlled, efficacy trials whe received ROZEREM were at least 65 years of age; of these, 199 were 75 years of age or older. No overall differences in safety

\section{ADVERSE REACTIONS}

Overvlow The data described in this section reffect exposure to ROZEREM in
jects, including 346 exposed for 6 months or longer, and 473 subjects for

one year.

Adverse Reactions Resulting In Discontinuation of Treatment
Five percent of the 3594 individual subjects exposed to ROZEREM in clinical studies discontinued treatment owing to an adverse event, compared with $2 \%$ of the 1370 subjects receiving placebo. The most frequent adverse events leading to discontinuation in subjects receiving ROZEREM were somnolence
$(0.8 \%)$, dizziness $(0.5 \%)$, nausea $(0.3 \%)$, fatigue $(0.3 \%)$, headache $(0.3 \%)$, and insomnia $(0.3 \%)$.

ROZEREM Most Commonly Observed Adverse Events in Phase 1-3 trials The incidence of adverse events during the Phase 1 through 3 trials
$(\%$ placebo, $n=1370 ; \%$ ramelteon $[8 \mathrm{mg}], n=1250)$ were: headache NOS $(\%$ placebo, $n=1370 ; \%$ ramelteon $[8 \mathrm{mg}], n=1250)$ were: headache NOS
$(7 \%, 7 \%)$, somnolence $(3 \%, 5 \%)$, ratigue $(2 \%, 4 \%)$, dizziness $(3 \%, 5 \%)$, nausea $(2 \%, 3 \%)$, insomnia exacerbated $(2 \%, 3 \%)$, upper respiratory tract
infection NOS $(2 \%, 3 \%)$, diarnea NOS $(2 \%, 2 \%)$, myalogia $(1 \%, 2 \%)$, depression $(1 \%, 2 \%)$, dysgeusia $(1 \%, 2 \%)$, arthralgia $(1 \%, 2 \%)$,

depression $(1 \%, 2 \%)$, dysgeusia $(1 \%, 2 \%)$, 'arthral
influenza $(0,1 \%)$, blood cortisol decreased $(0,1 \%)$

Because clinical trials are conducted under widely varying conditions, adverse reaction rates observed in the clinical trials of a drug cannot be directly conpared to rates in clinical trials of other drugs, and may not reflect the rates does, however, provide a basis for identitying the adverse events that appear does, however, provide a basis for identitying the adverse
to be related to drug use and for approximating rates.

to be related to drug use and for appro
DRUG ABUSE AMD DEPENDENCE

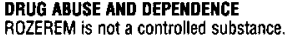

Human Data: See the CLIMICAL TRIALS section, Studies Pertinent to Sately Concerns for Sleep-Promettang Agents in the Complete Proscribing

Animal Data. Rametteon did not produce any signals from animal behavioral studies indicating that the drug produces rewarding effects. Monkeys did not self-administer ramelteon and the drug did not induce a conditioned place preference in rats. There was no generalization between ramelteon and midazolam. Ramelteon did not affect rotorod performance, an indicator of disruption of motor function, and it did

Discontinuation of ramelteon in animals or in humans after chronic administration did not produce withdrawal signs. Ramelteon does not appear to produce physicald

OVERDDSAGE

Signs and Symptoms
No cases of ROZEREM overdose have been reported during clinical develop-

ROZEREM was administered in single doses up to $160 \mathrm{mg}$ in an abuse liabilRecommended Treatment

Recommended Treatment
General symptomatic and supportive measures should be used, along with immediate gastric lavage where appropriate. Intravenous fluids should be administered as needed. As in all cases of drug overdose, respiration, pulse, general supportive measures employed.

Hemodialysis does not effectively reduce exposure to ROZEREM. Therefore, Polson Control Center

As with the management of all overdosage, the possibility of multiple drug ingestion should be considered. The physician may contact a pois
center for current information on the management of overdosage. Rx only

\section{Manufactured by:}

Takeda Pharmaceutical Company Limited

Manufactured in:

Kilruddery, County Wicklow, Republic of Ireland

Marketed by:

keda Pharmaceuticals America, Inc.

Lincoinshire, Road 60069

ROZEREM ${ }^{T}$ is a trademark of Takeda Pharmaceutical Company Limited and 政ed under license by Takeda Pharmaceuticals America, Inc.

Q2005, Takeda Pha rmaceuticals America, Inc.

P102-0002-1

oda Pharmaceuticals America,

c. 2. Data on file, Takeda Pharmaceuticals North America, Inc.

$1 / 06$

Printed in U.S.A. 